\title{
Use of sirolimus in the treatment of lymphangioleiomyomatosis: favorable responses in patients with different extrapulmonary manifestations*
}

\author{
Uso de sirolimo no tratamento de linfangioleiomiomatose: \\ resposta favorável em pacientes com diferentes \\ manifestações extrapulmonares
}

\author{
Carolina Salim Gonçalves Freitas ${ }^{1}$, Bruno Guedes Baldi², Mariana Sponholz Araújo르, \\ Glaucia Itamaro Heiden', Ronaldo Adib Kairalla ${ }^{3}$, Carlos Roberto Ribeiro Carvalho ${ }^{4}$
}

\begin{abstract}
Objective: Lymphangioleiomyomatosis (LAM) is a rare disease that is currently considered a low-grade neoplasm with metastatic potential and variable progression. Mammalian target of rapamycin (mTOR) inhibitors, such as sirolimus and everolimus, have recently become a treatment option for LAM patients, especially those with extrapulmonary manifestations. The objective of the present study was to describe a case series of four patients with LAM in Brazil who showed significant improvement, particularly in their extrapulmonary manifestations, after treatment with sirolimus (at 1-4 mg/day). Methods: We describe four cases of LAM patients with different extrapulmonary manifestations who were treated with sirolimus. Results: After treatment with sirolimus for 12 months, one patient presented resolution of severe chylothorax; one had a significant reduction in renal angiomyolipoma volume; and one showed significant regression of retroperitoneal lymphangioleiomyomas and abdominal lymph node enlargement. After treatment with sirolimus for 6 months, the remaining patient had a significant reduction in the volume of a massive retroperitoneal lymphangioleiomyoma. Conclusions: Our findings confirm that mTOR inhibitors are beneficial for patients with LAM, especially those with extrapulmonary manifestations, such as renal angiomyolipoma, lymphangioleiomyomas, and chylous effusions. However, certain aspects, such as the optimal dose, duration of treatment, and long-term adverse effects, have yet to be sufficiently clarified for mTOR inhibitors to be incorporated into LAM management protocols.
\end{abstract}

Keywords: Neoplasms; lymphangioleiomyomatosis/therapy; TOR serine-threonine kinases; Sirolimus.

\section{lntroduction}

Lymphangioleiomyomatosis (LAM) is a rare disease of unknown etiology. It primarily affects women of childbearing age, and the prevalence of LAM is approximately $1 / 1,000,000$ population. It can occur in isolation or in association with tuberous sclerosis complex (TSC). ${ }^{(1-3)}$ The disease is characterized by proliferation of atypical cells

(LAM cells) with characteristics of low-grade neoplasm and metastatic potential, leading to vascular and bronchial obstruction and cyst formation. $^{(4-8)}$

Major clinical manifestations of LAM include progressive dyspnea on exertion, dry cough, recurrent spontaneous pneumothorax, chylothorax,

1. Collaborating Physician. Department of Pulmonology, Instituto do Coração - InCor, Heart Institute - University of São Paulo School of Medicine Hospital das Clínicas, São Paulo, Brazil.

2. Attending Physician. Department of Pulmonology, Instituto do Coração - InCor, Heart Institute - University of São Paulo School of Medicine Hospital das Clínicas, São Paulo, Brazil.

3. Associate Professor. Department of Pulmonology, Instituto do Coração - InCor, Heart Institute - University of São Paulo School of Medicine Hospital das Clínicas, São Paulo, Brazil.

4. Full Professor. Department of Pulmonology, Instituto do Coração - InCor, Heart Institute - University of São Paulo School of Medicine Hospital das Clínicas, São Paulo, Brazil.

*Study carried out in the Department of Pulmonology, Instituto do Coração - InCor, Heart Institute - University of São Paulo School of Medicine Hospital das Clínicas, São Paulo, Brazil.

Correspondence to: Carolina Salim Gonçalves Freitas. Divisão de Pneumologia, Instituto do Coração - InCor - Hospital das Clínicas da Faculdade de Medicina da Universidade de São Paulo, Avenida Dr. Enéas de Carvalho Aguiar, 44, $8^{\circ}$ andar, bloco 2, CEP 05403-900, São Paulo, SP, Brasil.

Tel. 5511 2661-5191. Fax: 5511 2661-5695. E-mail: carolinasalim@gmail.com

Financial support: None.

Submitted: 13 January 2015. Accepted, after review: 8 April 2015. 
and hemoptysis..$^{(1,3,9)}$ Renal angiomyolipomas and lymphangioleiomyomas can occur. A CT scan of the chest typically shows the presence of diffuse, well-defined, thin-walled lung cysts. Although pulmonary function test results can be normal, variable and progressive lung function decline can occur over time. Reduced DLCO is the most common change, and spirometry most commonly reveals airflow obstruction and air trapping; bronchodilator test results can be positive in up to $25 \%$ of cases. ${ }^{(10-12)}$

A definitive diagnosis of LAM is based on the following ${ }^{(3,6)}$ :

- typical chest HRCT findings, i.e., diffuse, well-defined lung cysts, in association with renal angiomyolipoma, pleural effusion/ chylous ascites, lymphangioleiomyoma/ lymph node involvement, or a definite or probable diagnosis of TSC

- presence of lung cysts consistent with LAM on chest HRCT scans and pathological findings of LAM in a lung tissue sample preferably obtained by surgical biopsy

Determination of serum levels of VEGF-D, which is a marker of lymphangiogenesis, has been increasingly used in order to aid in the diagnosis of LAM and to evaluate disease progression. Chest CT findings consistent with LAM associated with elevated VEGF-D levels are currently considered to be sufficient for the diagnosis of LAM. ${ }^{(13,14)}$

The progression of LAM is highly variable, ranging from asymptomatic patients to patients with progressive respiratory failure requiring lung transplantation. Survival has been shown to be better in recent studies than in previous studies; a recent study conducted in Brazil showed a five-year survival of $90 \%$. $^{(15)}$

Various drugs have been used in an attempt to control LAM. Matrix metalloproteinase inhibitors, such as doxycycline, and hormonal blockade have yielded controversial results and are not recommended for the treatment of LAM. ${ }^{(16-19)}$ Mammalian target of rapamycin (mTOR) inhibitors, such as sirolimus and everolimus, are promising in the treatment of LAM, particularly in improving extrapulmonary manifestations and stabilizing or even improving lung function. ${ }^{(20,21)}$

The objective of the present study was to describe a case series of patients with LAM in Brazil treated with sirolimus, which had positive effects, particularly on extrapulmonary manifestations.

\section{Case series}

Of a total of 10 patients with LAM treated with sirolimus at our center during the study period, we describe four cases of patients in whom the drug was primarily used because of extrapulmonary involvement.

\section{Case 1}

A 48-year-old smoker (with a smoking history of 15 pack-years) was admitted with a two-year history of dyspnea, which had worsened one week prior. She reported no other diseases. The patient reported that she had undergone oophorectomy nine years prior because of a benign tumor and right nephrectomy six months prior because of renal angiomyolipoma. She had no relevant exposure history. Physical examination revealed that the patient had lost weight, breath sounds being absent in the right hemithorax and her $\mathrm{SpO}_{2}$ being $92 \%$ on room air. A chest X-ray showed a large right pleural effusion (Figure 1). The patient underwent thoracentesis, and a diagnosis of chylothorax was established. A pulmonary function test performed after chest tube drainage showed an FVC of $3.12 \mathrm{~L}$ (100\% of predicted), an FEV of $1.95 \mathrm{~L}$ (75\% of predicted), an $\mathrm{FEV}_{1} / \mathrm{FVC}$ ratio of 0.62 , a TLC of $5.27 \mathrm{~L}(92 \%$ of predicted), and a DLCO of $15.41 \mathrm{~mL} / \mathrm{min} /$ $\mathrm{mmHg}(65 \%$ of predicted; Table 1). A chest CT scan showed diffuse, well-defined lung cysts. Her dyspnea worsened, and she presented with difficult-to-manage chylothorax, with a high output from the chest tube despite treatment with total parenteral nutrition. A decision was made to treat her with sirolimus (at $1 \mathrm{mg} /$ day). Resolution of the chylothorax and functional stability were observed after 12 months of treatment (Figure 1 and Table 1).

\section{Case 2}

A 25-year-old patient diagnosed with LAM and TSC presented with a two-year history of recurrent pneumothorax and pleurodesis. She reported no smoking and had no relevant exposure history. Because of the neurological impairment associated with TSC, the patient had frequent convulsive seizures and a cognitive deficit. She also had large bilateral renal angiomyolipomas and had previously undergone a right partial nephrectomy because of hemorrhage. She had 


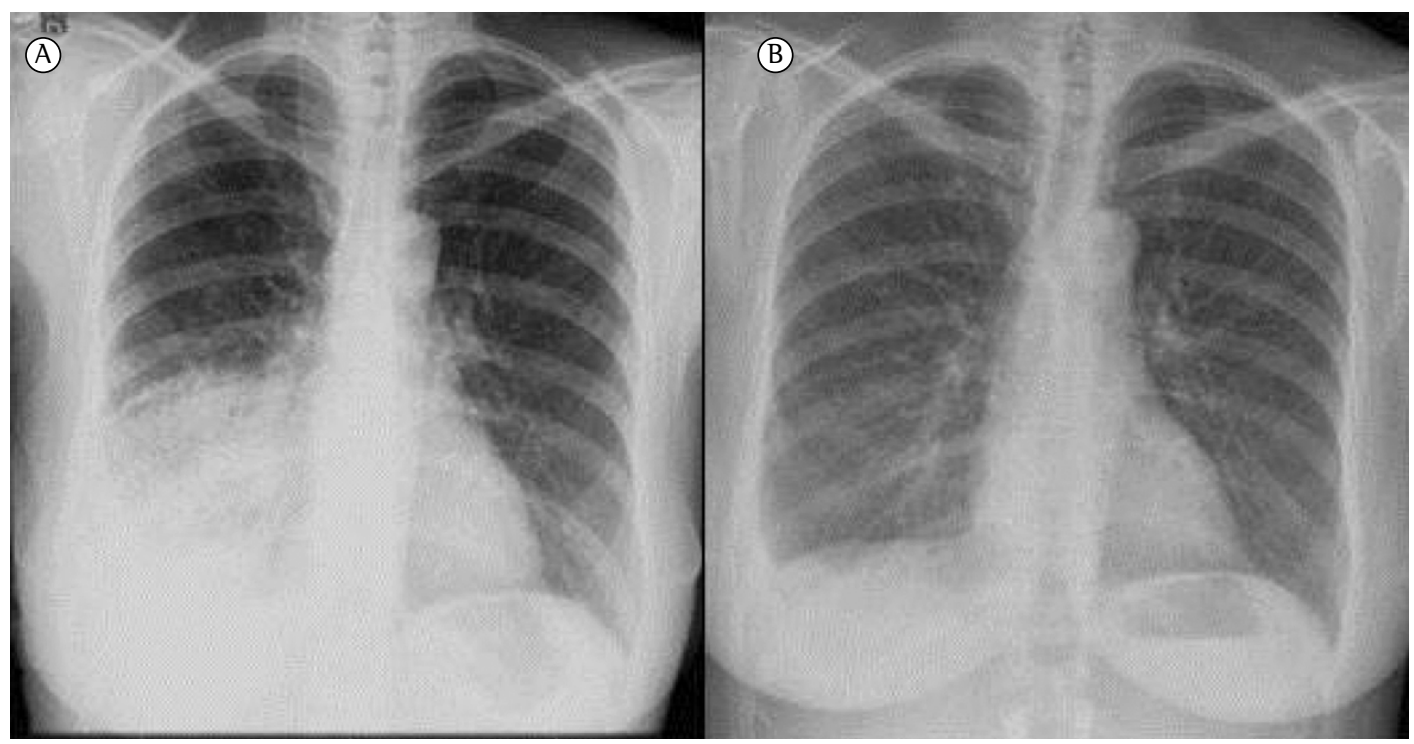

Figure 1 - Chest X-rays taken before treatment with sirolimus (in A) and after 12 months of treatment with the drug (in B), showing resolution of chylothorax.

Table 1 - Pulmonary function test results before and after treatment with sirolimus. ${ }^{\text {a }}$

\begin{tabular}{ccccccc}
\hline Case & \multicolumn{2}{c}{ FVC } & \multicolumn{2}{c}{ FEV $_{1}$} & \multicolumn{2}{c}{ DLCO } \\
\cline { 2 - 6 } & pre-treatment & post-treatment & pre-treatment & post-treatment & pre-treatment & post-treatment \\
\hline 1 & $3.12(100)$ & $3.22(103)$ & $1.95(75)$ & $2.0(77)$ & $15.41(65)^{\mathrm{b}}$ & $17.54(74)^{\mathrm{b}}$ \\
3 & $2.36(61)$ & $3.53(91)$ & $1.49(46)$ & $2.02(62)$ & - & - \\
4 & $3.96(90)$ & $3.92(89)$ & $3.37(89)$ & $3.4(90)$ & $20.12(98)^{\mathrm{b}}$ & $20.4(99)^{\mathrm{b}}$ \\
\hline
\end{tabular}

${ }^{a}$ Values expressed as L (\% of predicted), except where otherwise indicated. ${ }^{b}$ Values expressed as $\mathrm{mL} / \mathrm{min} / \mathrm{mmHg}(\%$ of predicted).

been using goserelin and doxycycline since 2010, and the renal tumor had progressively increased in the last two years. A decision was made to treat her with sirolimus, initially at $6 \mathrm{mg} /$ day and subsequently at $2 \mathrm{mg} /$ day because of nausea and vomiting. After 12 months of treatment, there was a significant reduction in the size of the angiomyolipoma (from approximately $20 \mathrm{~cm}$, with confluent masses, to approximately $3 \mathrm{~cm}$; Figure 2). Because of her cognitive deficit, the patient did not undergo pulmonary function testing.

\section{Case 3}

A 26-year-old nonsmoker with a three-year history of dyspnea on exertion presented with acute worsening of dyspnea. Although a large chylothorax was identified in 2011, it was not investigated at the time. One year later, the patient was admitted for investigation. Chest and abdominal CT scans showed diffuse cysts in the lung parenchyma, as well as large retroperitoneal lymphangioleiomyomas and abdominal lymph node enlargement. A diagnosis of LAM was established, and initial pulmonary function test results were as follows: FVC, $2.36 \mathrm{~L}$ (61\% of predicted); FEV, $1.49 \mathrm{~L}$ ( $46 \%$ of predicted); and $\mathrm{FEV}_{1} / \mathrm{FVC}, 0.63$. The patient was started on sirolimus (at $2 \mathrm{mg} /$ day) and after 12 months of treatment with the drug showed significant regression of the retroperitoneal and abdominal masses (Figure 3), as well as improved lung function (Table 1).

\section{Case 4}

A 37-year-old nonsmoker presented with diffuse abdominal pain. The patient had no respiratory symptoms, relevant exposure history, or associated diseases. During the investigation, a large, heterogeneous retroperitoneal mass of approximately $18 \mathrm{~cm}$ in size was identified. A biopsy was performed, and the mass was diagnosed as a lymphangioleiomyoma. A chest CT scan showed diffuse cysts in the lung parenchyma, whereas pulmonary function test results, including DLCO, were normal (Table 1). The patient was started 


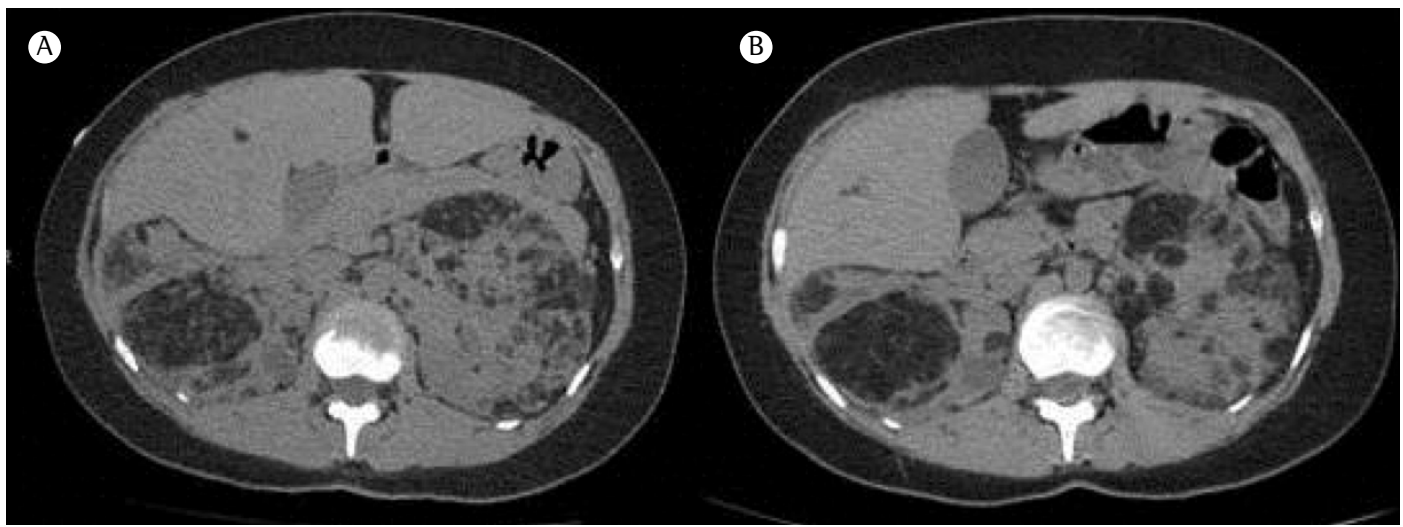

Figure 2 - Abdominal CT scans taken before treatment with sirolimus (in A) and after 12 months of treatment with the drug (in B), showing a reduction in bilateral renal angiomyolipoma volume.

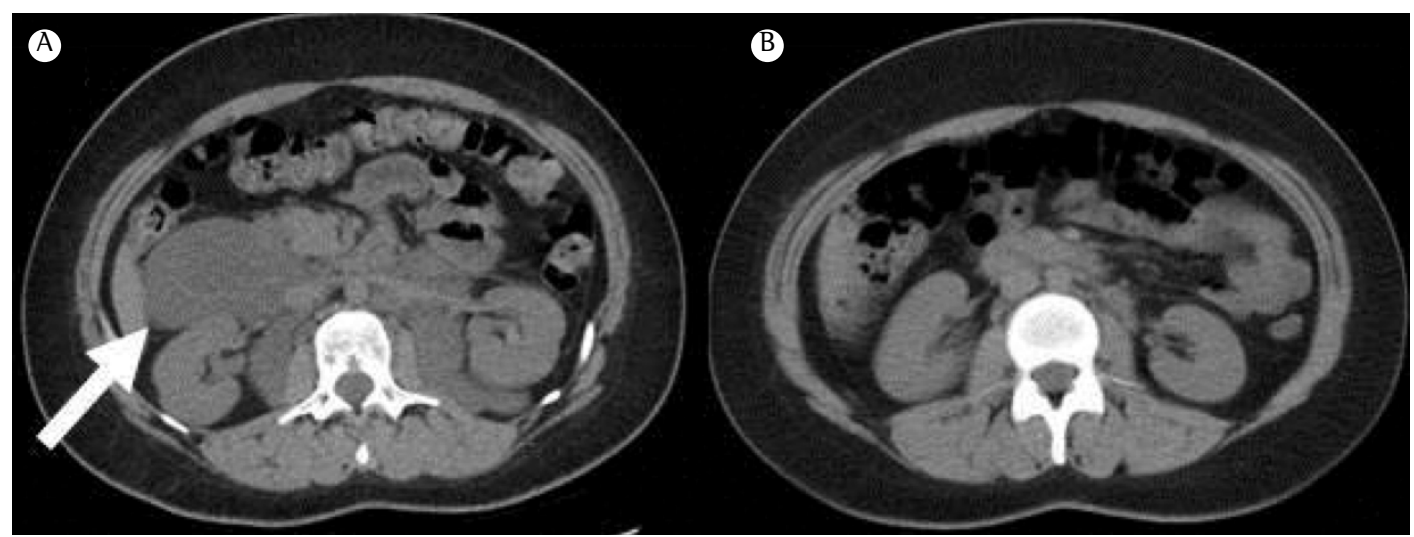

Figure 3 - Abdominal CT scans taken before treatment with sirolimus (in A) and after 12 months of treatment with the drug (in B), showing a significant reduction in retroperitoneal lymphangioleiomyoma volume (white arrow).

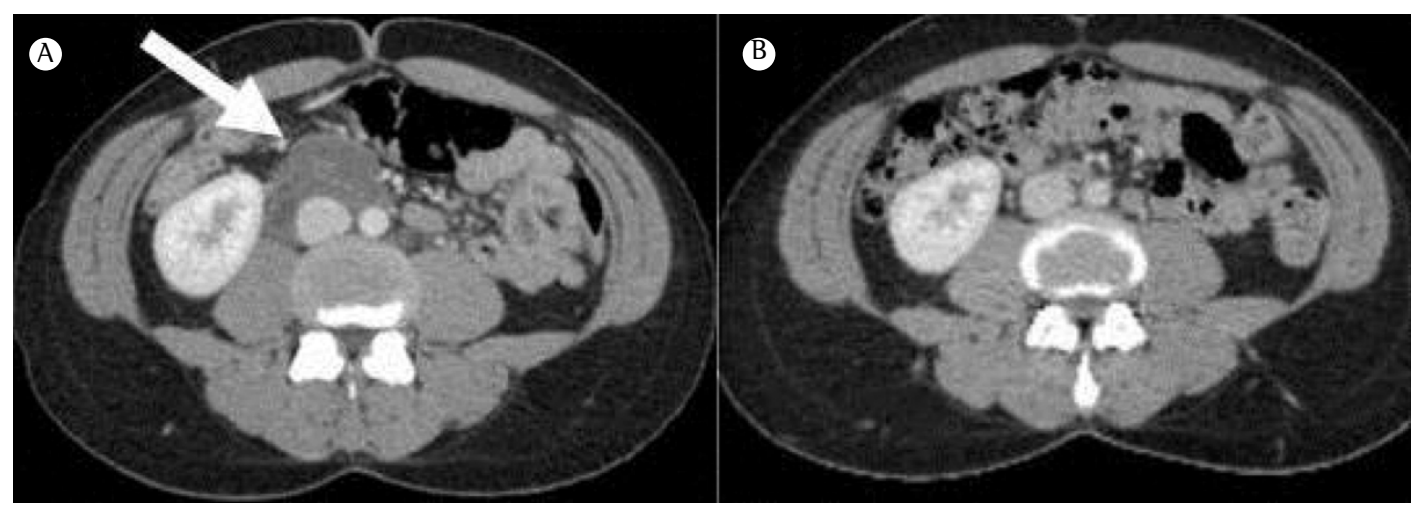

Figure 4 - Abdominal CT scans taken before treatment with sirolimus (in A) and after 6 months of treatment with the drug (in B), showing resolution of an abdominal lymphangioleiomyoma (white arrow).

on sirolimus (at $2 \mathrm{mg} /$ day) because of the size of the mass, which was symptomatic and posed a risk of hemorrhage. After 6 months of treatment with the drug, there was a significant reduction in lymphangioleiomyoma volume (Figure 4).

\section{Discussion}

In the four cases of patients with LAM described above, the use of sirolimus (at 1-6 $\mathrm{mg} /$ day) had positive effects, particularly on 
extrapulmonary manifestations, including a reduction in renal angiomyolipoma volume, abdominal mass volume, and retroperitoneal mass volume, as well as resolution of chylothorax.

On the basis of the various mechanisms involved in the pathophysiology of LAM, several drugs have been used in an attempt to control the disease. Although doxycycline blocks metalloproteinases, it is currently not recommended, because a recent randomized study showed that it had no effect on lung function. ${ }^{(16,17)}$ Hormonal blockade with the use of progesterone and gonadotropin-releasing hormone analogs has yielded controversial results and is currently not recommended. ${ }^{(18,19)}$

Mutations in the TSC 1 and TSC 2 genes, which can be found in patients with LAM, are associated with deregulation and hyperactivation of the mTOR pathway, which controls protein synthesis and cell growth. Inhibitors of mTOR inhibit T-lymphocyte activation and proliferation in response to antigenic and cytokine stimulation, binding to the FKBP-12 protein to form an immunosuppressive complex. This complex binds to mTOR, an important regulatory kinase, inhibiting its activity and ultimately blocking cell proliferation.

Recent evidence has shown that mTOR inhibitors are promising options for patients with LAM and can be used in cases of large renal angiomyolipomas and lymphangioleiomyomas, as well as in the control of chylothorax and chylous ascites; in addition, mTOR inhibitors have beneficial effects on lung function, particularly in patients with a rapid decline in respiratory capacity and mild to moderate airflow limitation, ${ }^{(20,22)}$ as observed in our case series.

Although the use of sirolimus in patients with LAM is promising, certain issues have yet to be clarified, including the need for determining serum levels of the drug (as is done in kidney or lung transplant recipients, for example), treatment duration, and long-term treatment safety. Recent studies have shown that it is possible to use sirolimus at lower doses in order to reduce adverse effects without compromising treatment efficacy. ${ }^{(23)}$ Doses of 1-2 mg/day are habitually used; however, in cases of large renal angiomyolipomas, higher initial doses can be used. A study by Yao et al. showed that the favorable effects of sirolimus on lung function remained after long-term treatment (approximately three and a half years) and that although adverse effects are common, including hypercholesterolemia, increased respiratory tract infections, diarrhea, and stomatitis, as well as acne and other skin disorders, they are usually mild and do not result in treatment discontinuation. ${ }^{(24)}$ However, the risk of recurrence after treatment discontinuation has yet to be determined.

Inhibitors of mTOR have become an important treatment option for selected cases of patients with LAM, especially those with significant extrapulmonary manifestations, such as renal angiomyolipomas, lymphangioleiomyomas, and chylous effusions. However, certain issues (such as the optimal dose and duration of treatment) have yet to be investigated in prospective studies for mTOR inhibitors to be permanently incorporated into LAM management protocols.

\section{References}

1. Glassberg MK. Lymphangioleiomyomatosis. Clin Chest Med. 2004;25(3):573-82, vii. http://dx.doi.org/10.1016/j. ccm.2004.05.003

2. Johnson SR. Lymphangioleiomyomatosis. Eur Respir J. 2006;27(5):1056-65.

3. Johnson SR, Cordier JF, Lazor R, Cottin V, Costabel $\mathrm{U}$, Harari S, et al. European Respiratory Society guidelines for the diagnosis and management of lymphangioleiomyomatosis. Eur Respir J. 2010;35(1):1426. http://dx.doi.org/10.1183/09031936.00076209

4. Pacheco-Rodriguez G, Kristof AS, Stevens LA, Zhang Y, Crooks D, Moss J. Giles F. Filley Lecture. Genetics and gene expression in lymphangioleiomyomatosis. Chest. 2002;121(3 Suppl):56S-60S. http://dx.doi.org/10.1378/ chest.121.3_suppl.56S

5. Matsui K, Beasley MB, Nelson WK, Barnes PM, Bechtle J, Falk R, et al. Prognostic significance of pulmonary lymphangioleiomyomatosis histologic score. Am J Surg Pathol. 2001;25(4):479-84. http://dx.doi. org/10.1097/00000478-200104000-00007

6. Pallisa E, Sanz P, Roman A, Majó J, Andreu J, Cáceres J. Lymphangioleiomyomatosis: pulmonary and abdominal findings with pathologic correlation. Radiographics. 2002;22 Spec No:S185-98. http://dx.doi.org/10.1148/ radiographics.22.suppl_1.g02oc13s185

7. Hayashi T, Fleming MV, Stetler-Stevenson WG, Liotta LA, Moss J, Ferrans VJ, et al. Immunohistochemical study of matrix metalloproteinases (MMPs) and their tissue inhibitors (TIMPs) in pulmonary lymphangioleiomyomatosis (LAM). Hum Pathol. 1997;28(9):1071-8. http://dx.doi. org/10.1016/S0046-8177(97)90061-7

8. McCormack FX, Travis WD, Colby TV, Henske EP, Moss J. Lymphangioleiomyomatosis: calling it what it is: a low grade, destructive, metastasizing neoplasm. Am J Respir Crit Care Med. 2012;186(12):1210-2. http:// dx.doi.org/10.1164/rccm.201205-08480E

9. Almoosa KF, Ryu JH, Mendez J, Huggins JT, Young LR, Sullivan EJ, et al. Management of pneumothorax in lymphangioleiomyomatosis: effects on recurrence and lung transplantation complications. Chest. 2006;129(5):127481. http://dx.doi.org/10.1378/chest.129.5.1274 
10. Yen KT, Putzke JD, Staats BA, Burger CD. The prevalence of acute response to bronchodilator in pulmonary lymphangioleiomyomatosis. Respirology. 2005;10(5):643-8. http://dx.doi.org/10.1111/j.1440-1843.2005.00762.x

11. Taveira-DaSilva AM, Hedin C, Stylianou MP, Travis WD, Matsui K, Ferrans VJ, et al. Reversible airflow obstruction, proliferation of abnormal smooth muscle cells, and impairment of gas exchange as predictors of outcome in lymphangioleiomyomatosis. Am J Respir Crit Care Med. 2001;164(6):1072-6. http://dx.doi.org/10.1164/ ajrccm.164.6.2102125

12. Baldi BG, Albuquerque AL, Pimenta SP, Salge JM, Kairalla RA, Carvalho CR. Exercise performance and dynamic hyperinflation in lymphangioleiomyomatosis. Am J Respir Crit Care Med. 2012;186(4):341-8. http:// dx.doi.org/10.1164/rccm.201203-03720C

13. Glasgow CG, Avila NA, Lin JP, Stylianou MP, Moss J. Serum vascular endothelial growth factor-D levels in patients with lymphangioleiomyomatosis reflect lymphatic involvement. Chest. 2009;135(5):1293-300. http:// dx.doi.org/10.1378/chest.08-1160

14. Young LR, Vandyke R, Gulleman PM, Inoue Y, Brown KK, Schmidt LS, et al. Serum vascular endothelial growth factor-D prospectively distinguishes lymphangioleiomyomatosis from other diseases. Chest. 2010;138(3);674-81. http://dx.doi.org/10.1378/ chest.10-0573

15. Baldi BG, Freitas CS, Araujo MS, Dias OM, Pereira DA, Pimenta SP, et al. Clinical course and characterisation of lymphangioleiomyomatosis in a Brazilian reference centre. Sarcoidosis Vasc Diffuse lung Dis. 2014;31(2):129-35.

16. Chang WY, Cane JL, Kumaran M, Lewis S, Tattersfield AE, Johnson SR. A 2-year randomised placebo-controlled trial of doxycycline for lymphangioleiomyomatosis. Eur Respir J. 2014;43(4):1114-23. http://dx.doi. org/10.1183/09031936.00167413

17. Pimenta SP, Baldi BG, Kairalla RA, Carvalho CR. Doxycycline use in patients with lymphangioleiomyomatosis: biomarkers and pulmonary function response. J Bras
Pneumol. 2013;39(1):5-15. http://dx.doi.org/10.1590/ S1806-37132013000100002

18. Baldi BG, Medeiros Junior P, Pimenta SP, Lopes Rl, Kairalla RA, Carvalho CR. Evolution of pulmonary function after treatment with goserelin in patients with lymphangioleiomyomatosis. J Bras Pneumol. 2011;37(3):375-9. http://dx.doi.org/10.1590/ S1806-37132011000300015

19. Harari S, Cassandro R, Chiodini l, Taveira-DaSilva AM, Moss J. Effect of a gonadotrophin-releasing hormone analogue on lung function in lymphangioleiomyomatosis. Chest. 2008;133(2):448-54. http://dx.doi.org/10.1378/ chest.07-2277

20. McCormack FX, Inoue Y, Moss J, Singer LG, Strange C, Nakata K, et al. Efficacy and safety of sirolimus in lymphangioleiomyomatosis. $\mathrm{N}$ Engl $\mathrm{J}$ Med. 2011;364(17):1595-606. http://dx.doi.org/10.1056/ NEJMoa 1100391

21. Taveira-DaSilva AM, Hathaway 0, Stylianou M, Moss J. Changes in lung function and chylous effusions in patients with lymphangioleiomyomatosis treated with sirolimus. Ann Intern Med. 2011;154(12):797-805, W-292-3.

22. Neurohr C, Hoffmann AL, Huppmann P, Herrera VA, lhle F, Leuschner $\mathrm{S}$, et al. Is sirolimus a therapeutic option for patients with progressive pulmonary lymphangioleiomyomatosis? Respir Res. 2011;12:66. http://dx.doi.org/10.1186/1465-9921-12-66

23. Ando K, Kurihara M, Kataoka H, Ueyama M, Togo S, Sato T, et al. Efficacy and safety of low-dose sirolimus for treatment of lymphangioleiomyomatosis. Respir Investig. 2013;51(3):175-83. http://dx.doi.org/10.1016/j. resinv.2013.03.002

24. Yao J, Taveira-DaSilva AM, Jones AM, JulienWilliams P, Stylianou M, Moss J. Sustained effects of sirolimus on lung function and cystic lung lesions in lymphangioleiomyomatosis. Am J Respir Crit Care Med. 2014;190(11):1273-82. http://dx.doi.org/10.1164/ rccm.201405-09180C 